\title{
PREFACE: ENHANCED HEAT AND MASS TRANSFER AT LOW-TEMPERATURE APPLICATIONS IN LIFE SCIENCES AND CHEMICAL ENGINEERING
}

This special issue includes articles that address different aspects of heat- and mass-transfer processes at low temperatures for a spectrum of applications in natural sciences and chemical engineering.

It is so amazing that in the 20th, and beginning of the 21st, centuries nine Nobel Prizes were awarded for discoveries and research of physical phenomena, for which the work was performed using temperatures below the ambient level. This illustrates that at such temperatures, the "density of knowledge" per $1^{\circ} \mathrm{K}$ can potentially be very high. With this in mind, we did not implement a selection of articles, nor provide authors with a podium, for a variety of research topics. The only requirement was that all processes needed to be performed using temperatures below the ambient level.

In this issue, two of the articles are devoted to the field of cryosurgery, two cover frozen meat production and food preservation, and another three review processes used in distillation columns and heat exchangers. Another article describes methodology and calculation results of convective heat transfer near a hypersonic aircraft surface at ongoing airstream temperature near $60^{\circ} \mathrm{K}$. All of the articles involve numerical modeling, computation, and experimental research of heat and mass transfer at low temperatures. A fair amount of previous research worldwide shows that the typical standard models and algorithms with excellent approaches at high temperatures cannot be applied for processes used at a low-temperature range. A clear understanding of heatand mass-transfer features at low temperatures can help to improve theory and implement new processes of energy-saving and -generation technologies; expand our knowledge of food storage, thermal clothing design, and body and skin thermal treatment during cryogenic application or cryotherapy; and broaden our understanding of hypersonic motion in the stratosphere.

This special issue is the first $J E H T$ effort to bring special attention to the research and engineering community on heat- and mass-transfer mechanisms occurring at below ambient temperature, its features, and methods for enhancement.

As guest editor of this issue, I am grateful to all of the contributing authors for their challenging research efforts that they have decided to share with the worldwide thermal and fluids engineering community.

\section{Guest Editor:}

Ivan A. Arkharov

Bauman Moscow State Technical University

IIR-A1 Cryophysics and Cryoengineering

Moscow, Russia 